\title{
RESTRIÇÕES ORÇAMENTÁRIAS E ENTREGA DE VALOR: SINERGIAS ENTRE BIM E CUSTEIO-META
}

\author{
Cost constraints and value delivery: synergies \\ between BIM and target costing
}

Marcelo de Morais', Ariovaldo Denis Granja', Regina Coeli Ruschel'

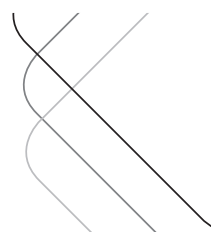

RESUMO O target costing ou custeio-meta (CM) é uma abordagem que teve sua origemna indústria manufatureira que tem como objetivo proporcionar a redução de custo sem diminuik a qualidade e o valor do produto aos olhos do cliente e começou a ser utilizada na indústria da construção civil em diversos países. Um aspecto relevante para sua implementação na indústria da construção civil é a qualidade da informação e interação das equipes nas fases iniciais de um empreendimento. O uso da Modelagem da Informação da Construção (BIM) permite a extração de informações de forma rápida e precisa no início da elaboração do projeto, por exemplo, na forma de quantitativos e custos. O artigo tem como objetivo explorar a sinergia existente entre o CM e o BIM, apontando quais os benefícios proporcionados por essa união. Este é um estudo secundário por meio de revisão de literatura de estudos primários sobre CM e BIM com o objetivo de sintetizar os resultados e explorar a possível sinergia do uso integrado dessas abordagens. Os resultados evidenciam os aspectos positivos dessa utilização conjunta. As conclusões apontam para diversos benefícios e estratégias para que ocorra sinergia, tais como a quantificação automática, estímulo à criatividade, avaliação de alternativas de custos e a integração das equipes em novas formas de contratação.

'Universidade Estadual de Campinas

PALAVRAS-CHAVE: BIM, custeio-meta, modelo de custos.

ABSTRACT Target costing (TC) is an approach that has its origins in the manufacturing industry that aims to provide cost savings without reducing the quality and value of the product to the customer's eyes and has been used in the construction industry in various countries. One aspect relevant to its implementation in construction industry is the quality of information and interaction of the teams in the early stages of a project. The use of Building Information Modeling (BIM) allows the extraction of information quickly and accurately at the beginning of the project design, for instance, quantities and costs estimation. The paper aims to describe the synergy between TC and BIM, pointing out the positive aspects offered by this union. This is a secondary study using literature review of primary studies on TC and BIM to synthesize the results and to explore a possible synergy integrating both approaches. The results show the positive aspects of joint use. The findings point to several benefits and strategies for this synergy to occur, such as automatic quantification, stimulating creativity, assessment of cost alternatives and the integration of the teams in new forms of employment.

KEYWORDS: BIM, target-costing, cost model.

\section{How to cite this article:}

MORAIS, M.; GRANJA, A. D.; RUSCHEL, R. C. Restrições orçamentárias e entrega de valor: sinergias entre BIM e custeio-meta. Gestão e Tecnologia de Projetos, São Paulo, v. 10, n. 1, p. 7-27, jan./jun. 2015

http://dx.doi.org/10.11606/gtp.v10i1.81141
Fonte de financiamento:

Declaram não haver.

Conflito de interesse:

Declaram não haver

Submetido em: 05 mar. 2015

Aceito em: 06 maio 2015 


\section{INTRODUÇÃO}

No contexto atual da construção civil, resolver a aparente incompatibilidade entre a necessidade de redução de custos nos empreendimentos do setor e, ao mesmo tempo, assegurar a entrega de valor na percepção do cliente ou usuário final adquire grande relevância. O target costing ou custeio-meta (CM) tem sido proposto como um dos métodos potenciais para resolver essa incompatibilidade. As interações nas análises de custos e a sua efetividade na entrega de valor ao cliente ou usuário final, típicas do CM, podem ser catalisadas com o uso do Building Information Modeling (BIM).

Poucas foram as pesquisas que procuraram investigar a possível sinergia entre o CM e o BIM na construção civil. Este artigo apresenta o resultado de uma pesquisa bibliográfica que teve como objetivo investigar a interação entre a abordagem do CM e o conceito BIM, assim como identificar quais características relevantes do BIM podem auxiliar na aplicação do CM na indústria da construção civil. Trata-se, portanto, de um estudo secundário objetivando sintetizar os resultados e apresentar evidências dos estudos primários já publicados. O foco do estudo está nas questões relativas ao uso de modelos de informação da construção e o CM.

$\mathrm{O}$ artigo apresenta, também, um caso bem-sucedido de utilização de BIM e CM, realizado em um prédio hospitalar na Califórnia - Sutter Medical Center Castro Valle. Optou-se por citar o caso, pois este foi modelo para implementação de outros projetos do setor hospitalar na Califórnia, pioneiro na utilização de novas formas de contratação como o Integrated Project Delivery ${ }^{\mathrm{TM}}$ (IPD) e uso de modelos BIM para gerenciar o CM no empreendimento.

Desejou-se sintetizar o conhecimento acumulado sobre o tema. Sendo assim, o trabalho desenvolve uma discussão teórica sobre o assunto, sendo apresentado como resultado parcial de pesquisa vinculada à Rede Cooperativa de Pesquisa FINEP de Tecnologias da Informação de Comunicação Aplicadas à Construção de Habitação de Interesse Social (TICHIS). Verificou-se uma sinergia entre o BIM e o CM por meio das informações passíveis de serem geradas pelos modelos, tal como a extração de quantitativos de forma rápida e precisa para apoiar decisões em fases iniciais de concepção, as quais contribuem para a abordagem proativa e para a análise de alternativas de custo no desenvolvimento de produtos da construção civil. Finalizando, o artigo apresenta um panorama das pesquisas em que o CM utiliza o ferramental BIM como suporte ao processo de tomada de decisão.

\section{CUSTEIO-META}

Vários autores, como Monden (1995), Nicolini et al. (2000), Yook et al. (2005) e Okano e Suzuki (2007), atribuem a origem do CM à indústria automobilística japonesa no início da década de 1960. Segundo Moden (1995), a Toyota foi a primeira a desenvolver o CM, que surgiu da necessidade da competitividade de preço e redução de custos entre os fabricantes de automóveis. Hoje, o CM é usado não apenas na indústria automotiva, mas também em outras áreas da indústria de manufatura.

Porém, há indícios de que a Ford utilizou conceitos relacionados ao $\mathrm{CM}$ para desenvolver o Modelo T, fixando um valor estimado indicativo para seu desenvolvimento (COOPER; SLAGMULDER, 1997). A Volkswagen também utilizou conceitos da abordagem para desenvolver o Fusca em 1930 (FEIL; YOOK; KIM, 2004 apud JACOMIT; GRANJA, 2011). Tais fatos salientam que a indústria japonesa incorporou esses conceitos e a engenharia de valor, transformando a abordagem do CM como é conhecida atualmente. Além da indefinição da origem da abordagem, não há consenso sobre sua definição.

Para Nicolini et al. (2000), o CM é entendido como uma ampla prática de gestão estratégica que dá relevância à coordenação da cadeia de suprimento, com intuito de obter vantagem competitiva via entrega de um produto para o qual haverá demanda de compradores. 
Para Ansari et al. (1997), CM é um sistema para gerenciamento de custos e planejamento dos lucros realizado de forma multidisciplinar, baseado no preço de mercado, e tem como meta atender às necessidades do cliente.

Moden (1995) define o CM como um sistema de gerenciamento de custos que envolve níveis competitivos de custos e preços e que garanta a lucratividade, e tem como objetivo oferecer produtos com qualidade, com preços acessíveis e que agradem aos clientes.

De acordo com Cooper e Slagmulder (1997), o CM é definido por uma estratégia de desenvolvimento de novos produtos, sendo que o custo passa a ser um dos fatores que irão influenciar diretamente sua concepção. Este, por sua vez, pode ser influenciado por três fatores de custeio baseados no mercado, no nível do produto e no nível do componente, sendo necessário um tipo de esforço distinto para quebrar as barreiras de custo do produto em cada parte do processo, e cada fator determina uma relação específica com o produto e sua produção (COOPER; SLAGMULDER, 1997).

Para Ballard (2008), o CM é um método de desenvolvimento do produto que garante ao cliente a entrega de valor levando-se em consideração as restrições orçamentárias. Esse método deve ser entendido como uma filosofia de gestão empresarial que implica necessidades de melhoria contínua e inovação constantes.

Percebe-se que não há um consenso sobre o $\mathrm{CM}$, alguns definem como sistema, processo, método de desenvolvimento do produto, prática de gestão estratégia. No contexto deste trabalho, CM é compreendido como um sistema proativo para o gerenciamento de custos no desenvolvimento de novos produtos na indústria de $\mathrm{AECO}$ e não se restringe apenas a uma ferramenta para gerenciamento de custos. Dessa forma, CM tem como objetivo reduzir os custos, sem perder a qualidade e demais atributos que adicionam valor na perspectiva do cliente.

O termo Target Value Design(TVD) vem sendo adotado como uma adaptação mais recente do CM para a construção civil. A menção ao termo TVD surgiu pela primeira vez em um artigo escrito por Hal Macomber, Gregory Howell e Jack Barberio (2007), e passou a ser utilizado principalmente pela indústria de Arquitetura, Engenharia, Construção e Operação (AECO) nos EUA. Segundo Zimina et al. (2012), o TVD é utilizado em contextos altamente colaborativos na construção civil que pressupõem a adoção do Integrated Project Delivery ${ }^{\mathrm{TM}}$ (IPD) e do Integrated Form of Agreement (IFOA) no empreendimento. Vários autores apresentam os aspectos de utilização e caracterização do CM.

Para Ballard e Reiser (2004), o CM é utilizado inicialmente na concepção de um produto e nas suas modificações posteriores pertinentes ao processo de fabricação e ao longo do seu ciclo de vida e deve ter seu foco ao longo do processo como um todo.

Segundo Yook, Kim e Yoshikawa (2005), a utilização do CM na construção civil tem se ampliado no Japão. A primeira constatação da aplicação integral da abordagem do CM na construção civil foi em 1997 pelo governo japonês, na construção de obras públicas, com uma série de adaptações necessárias às peculiaridades da construção civil.

Entre as empresas japonesas, os resultados mais significativos com a adoção do CM foram, primeiramente, o envolvimento de um número maior de funcionários no processo para reduzir custos e a compra de insumos por melhores preços e, finalmente, a redução dos custos na construção (YOOK; KIM; YOSHIKAWA, 2005).

O CM utiliza os custos como parâmetro de entrada para o desenvolvimento do produto e, consequentemente, exerce influência na gestão do processo de projeto. Restrições orçamentárias, bastante frequentes em empreendimentos do setor, devem ser levadas em consideração no processo de desenvolvimento do produto, utilizando-se ferramentas tais como a Engenharia de Valor e modelos BIM para apoio à tomada de decisão ao longo da gestão do processo de projeto. Isso também potencializa a interação e a colaboração entre os agentes envolvidos, permitindo evoluções projetuais ao longo de seu desenvolvimento e por meio de workshops (BALLARD; REISER, 2004). 
Para Monden (1995), o CM tem como uma de suas características incorporar a administração do lucro em todo o processo de elaboração de um produto na empresa. Para que isso ocorra, é necessário o envolvimento de todos os setores. Inicialmente, deve ser realizado um plano para verificar a qualidade do produto aos olhos do cliente. Em seguida, deve ser realizada uma pesquisa em relação ao custo do produto no mercado (garantindo-se, assim, o lucro necessário que se deve atingir ao definir o custo-meta) e, finalmente, os esforços devem garantir que ocorra a redução dos custos e a satisfação do cliente (MONDEN, 1995).

Outra característica da abordagem do $\mathrm{CM}$ é considerar o custo, a funcionalidade e a qualidade do produto como parâmetros determinantes na fase inicial de desenvolvimento do projeto. Tais fatores irão orientar a intenção de se projetar para um determinado valor, ou custo-meta. O uso de modelos 3 $\mathrm{D}^{1}$ pode potencializar a interação e a colaboração entre os agentes envolvidos no desenvolvimento do projeto na construção civil, permitindo evoluções projetuais do modelo ao longo de seu desenvolvimento, visando atingir as restrições presentes no empreendimento, na maioria das vezes orçamentárias (WHINCH, 2002).

Segundo Ballard (2008), deve haver um esforço para se reduzir o desperdício em todo o ciclo do projeto e orçamento; também é necessário que ocorra uma mudança fundamental de pensamento de "custos esperados" para metas de custo, bem como o envolvimento de diversas equipes funcionais sem pressupor que apenas um agente detenha todo o conhecimento. Finalmente, o uso do CM pressupõe um projeto integrado, desenvolvido em ambientes colaborativos, ou seja, um processo de custo ligado ao modelo da informação da construção (BALLARD, 2008).

\section{BIM}

O paradigma BIM é definido por Eastman et al. (2011) como uma tecnologia de modelagem e de processos associados para produzir, analisar e comunicar modelos com as informações de edifícios. Uma de suas principais características é o uso de modelos paramétricos e está fundamentada na interoperabilidade e colaboração entre os diversos profissionais da indústria da construção civil. Com a criação do modelo de informação da construção, é possível gerar, de forma automática, documentos, desenhos, quantitativos, entre outras informações, continuamente atualizadas e vinculadas entre si (EASTMAN et al., 2011).

Ainda de acordo com Eastman et al. (2011), o BIM se adequa ao uso da engenharia de valor no desenvolvimento de produtos da construção civil por meio de estimativas de custos e programação contínua, integradas na concepção do projeto. Facilita-se, assim, a tomada de decisão nas fases iniciais de projeto como análise de viabilidade por meio das estimativas de custo. Pode ainda subsidiar o gerenciamento da construção civil, como suporte à implantação de abordagens inovadoras como o IPD.

$\mathrm{O}$ detalhamento na modelagem é outro aspecto importante quando o foco é a extração de custos, checagem de conflitos e análise de desempenho. Eastman et al. (2011) descrevem a importância da maturidade e da evolução dos detalhes entre as fases de desenvolvimento do empreendimento, que vão da concepção à construção.

Bedrick (2008) descreve os níveis de desenvolvimento do modelo como LOD (Level of Development), uma forma lógica de como um modelo BIM deve evoluir, indo do menor nível de desenvolvimento, na etapa conceitual do projeto até o maior nível de precisão e representação na etapa de construção,

Segundo Winch (2002), o uso de modelos 3D com tecnologia object orientated database (OODB), lançado pela Bentley em 2000, elimina algumas limitações presentes no gerenciamento de documentos eletrônicos gerados por desenhos em CAD como: o esforço na interação baseada em desenhos impressos, os desenhos não contêm informações extras como quantitativos, e os trabalhos são realizados de forma dissociada, sendo que os projetistas não podem trabalhar simultaneamente em um mesmo modelo. 
fabricação e operação. A especificação desses níveis de desenvolvimento ou Model Progression Specification (MPS), segundo o autor, foi iniciada pela Vico ${ }^{2}$ e Webcor ${ }^{3}$, e posteriormente desenvolvida pela subcomissão de tecnologia do The American Institute of Architects da Califórnia - AIA (2008), e passou a ser adotada pela mesma em 2008, por meio do protocolo E $202^{\mathrm{TM}}$ 2008, Building Information Modeling Protocol (BEDRICK, 2008).

Segundo AIA (2008), independentemente das ferramentas utilizadas, todos os modelos devem seguir a mesma classificação padrão de objetos determinados pela National Building Information Model Standard (NBIMS). Além disso, o responsável pela gestão do modelo deverá facilitar a implementação dos protocolos de modelagem. Os protocolos são relativos às padronizações e às definições dos papéis de modelagem de cada indivíduo durante a criação e o compartilhamento dos arquivos em formato digital.

Alguns desses protocolos são relativos ao(s) modelo(s) criados como: a definição do sistema de coordenadas, ponto de origem do modelo, das unidades de trabalho, do local de armazenamento do(s) arquivo(s) etc.

Outros, relativos à segurança nos procedimentos de transferência de dados em meio digital, como: ao acessar o(s) modelo(s) para detecção de conflitos, ao realizar alteração(ões) no(s) modelo(s), ao criar modelo(s) específicos para cada disciplina, ao estabelecer os direitos de acesso(s) e alterações do(s) modelo(s), dentre outros, a serem definidos quando necessário.

As descrições dos LOD servem para identificar os requisitos de conteúdo específicos e associados para cada modelo, definindo seis níveis progressivos de desenvolvimento de 100 até 500. Cada LOD subsequente baseia-se no nível anterior e inclui todas as suas características, possuindo um incremento de detalhes que são adicionados gradualmente. Esses níveis são descritos a seguir (AIA, 2008, 2013).

O nível conceptual (100) é equivalente à fase inicial de concepção ou estudo volumétrico do projeto; o modelo é constituído de toda a volumetria global da construção e pode realizar algumas análises de construção, tais como: definir a forma inicial da edificação, a orientação do edifício e o seu custo por metro quadrado.

O segundo nível de desenvolvimento, approximate geometry (200), é comparado à fase de concepção do projeto ou anteprojeto e possui parte da sua geometria já definida, com quantitativos aproximados, tamanho e formas predefinidos. Há a representação parcial das instalações prediais, sendo que, nessa fase, a orientação do edifício e sua localização já estão definidas. É possível anexar informações aos componentes do modelo, permitindo a realização de análises de desempenho e quantitativos aproximados vinculados aos componentes.

No terceiro nível, precise geometry (300), o projeto está praticamente definido, possuindo a especificação dos materiais, os quantitativos já precisos e refletindo o que será construído no canteiro. É possível gerar a documentação para a obra, a lista de compras, bem como anexar o cronograma da obra em uma macroescala (sem detalhes de montagem). Isso permite a realização de diversas análises simulando o comportamento do edifício, englobando instalações prediais. O modelo pode ser utilizado para a construção, aproximando-se dos detalhes da fase de fabricação.

No quarto nível, assemblies for coordination (350), os níveis de desenvolvimento são suficientes para a coordenação, compatibilização e checagem de conflitos entre disciplinas (arquitetura, estrutural e sistemas prediais). Definem-se nessa fase os escopos de projeto por disciplina e o nível de desenvolvimento do modelo que possam garantir a compatibilização entre os projetos como de estrutura e hidráulica, prevendo, muitas vezes, o

\footnotetext{
A Vico Software Inc. é uma softhouse americana que também presta serviços para a indústria da construção civil, especializada em gerenciamento da construção. Disponível em: <http://www.vicosoftware.com>. Acesso em: 27 jul. 2015.

Webcor é uma empresa americana especializada tanto no desenvolvimento projetos quanto na construção civil. Disponível em: <http://www.webcor.com>. Acesso em: 27 jul. 2015.
} 
detalhamento de reforços, conexões da estrutura que possam influenciar na sua compatibilização $0^{4}$.

Na etapa fabrication (400), o modelo está pronto para a construção e fabricação. Para a execução desse modelo, é essencial a participação de todos os envolvidos no processo. Os detalhes do cronograma de obras devem estar vinculados ao modelo, que reflete o processo relativo da montagem (assembly) da obra. Essa fase permite simulações precisas e processos de manufatura dos componentes.

O último LOD, as built (500), reflete como o modelo foi construído e é considerado ideal para a realização da operação, da manutenção e de reformas.

No estudo realizado por Leite et al. (2011), observa-se a importância de definições dos LOD necessários para executar cada tarefa que se deseja atingir como: detecção de conflitos de instalações, extração de quantitativos, análise de desempenho, dentre outros. Dessa forma, pode-se otimizar o tempo de modelagem e atingir os objetivos propostos, viabilizando-se a definição de parâmetros para a utilização conjunta de BIM e CM.

\section{MÉTODO DA PESQUISA}

O método de pesquisa adotado para o desenvolvimento do artigo foi a pesquisa bibliográfica. $O$ estudo se caracteriza como secundário por meio de revisão de literatura de estudos primários com foco em BIM e CM, visando sintetizar os resultados e identificar benefícios do uso combinado dessas abordagens. O delineamento da pesquisa se deu com a definição do tema, do levantamento bibliográfico preliminar, da formulação do problema. Para isso, foi elaborado um plano provisório de assunto e, posteriormente, a busca das fontes, leitura do material e a organização lógica do tema para a redação do artigo (GIL, 2010).

Na fase do plano provisório de assunto, buscaram-se publicações que apresentassem os temas BIM, CM, target costing ou target value design correlacionados no mesmo artigo. Foram definidos dois critérios básicos para a coleta do material final: o temporal e o filtro de publicações. O critério temporal estabeleceu a abrangência dos estudos entre 2002 e 2012. Já o filtro de publicações definiu a seleção de artigos por meio da identificação das palavras-chave $\mathrm{CM}$ ou target costing ou target value design e BIM no título e resumo dos estudos.

A busca das fontes ocorreu em websites de busca como Google Acadêmico e bases de referências bibliográficas como Web of Science e Scopus. Também houve a seleção de teses, dissertações e livros relevantes sobre o tema. Esse processo também incluiu publicações contidas no International Group for Lean Construction (IGLC), no Journal Automation in Construction, no AECbytes e no Journal of Construction Engineering and Management.

Para a organização da estrutura lógica do assunto, adotou-se o processo de argumentação lógica proposto por Groat e Wang (2002). Segundo os autores, a estratégia de pesquisa de argumentação lógica consiste na capacidade de dar ordem lógica a um conjunto de fatores previamente díspares. Dessa forma, enquadram-se de forma lógica sistemas conceituais que ainda não estavam relacionados, devido a interconexões anteriores desconhecidas ou não sistematização de fatos relevantes associados (GROAT; WANG, 2002, p. 301-302).

O desenvolvimento da argumentação lógica baseou-se na fundamentação teórica e analítica abordada nas seções 2 e 3. Explicitou-se a argumentação lógica nos relatos de casos práticos da incorporação de BIM e CM publicados em artigos científicos resultantes da etapa de busca de fontes.

O LOD 350 não está incluído nos documentos E202 $2^{\mathrm{TM}}-2008$, Building Information Modeling Protocol G202 ${ }^{\mathrm{TM}}$-2013, Project Building Information Modeling Protocol Form, elaborados pela AIA, que surgiu devido à necessidade identificada pelo grupo de trabalho do BIMForum de se criar um modelo com desenvolvimento necessário que facilitasse a coordenação entre disciplinas e fosse detalhado e acrescentado ao Guide and Instructions do BIMForum (BEDRICK, 2013). 
Primeiramente, os casos práticos são caracterizados em termos de CM pelo tipo de contrato, práticas declaradas e pela forma de interação para atingir o CM (seção 2). Em seguida, os casos práticos são caracterizados em termos de BIM, identificando-se o nível de desenvolvimento do modelo de informação empregado (seção 3). A sinergia entre BIM e CM é explicitada nos benefícios, relatados nos casos práticos, que suportam a abordagem de CM como: (1) custo automatizado; (2) estímulo à criatividade - alternativa de solução; (3) colaboração, otimização e controle de processo; (4) rapidez de feedback.

Também são apresentadas as dificuldades relatadas relativas à implementação de BIM no contexto de CM. As dificuldades apontam barreiras que impedem maior sinergia entre essas abordagens. O nível de desenvolvimento do modelo de informação indica os usos de BIM propiciados pela sinergia encontrada.

Visando ilustrar a adoção de BIM e CM de forma mais detalhada, optouse por apresentar como exemplo o caso do Sutter Medical Castro Valley, na Califórnia, na seção 5, por ser um exemplo bem-sucedido e uma referência na adoção de BIM e CM nos EUA, além do caso do Sutter Medical Castro Valley possuir uma grande disponibilidade de dados provenientes das publicações levantadas e das informações sobre o processo de integração e colaboração presente no empreendimento, contribuindo, assim, para ilustrar a sinergia entre as duas abordagens.

\section{SÍNTESE dO CASO SUTTER MEDICAL CENTER, CASTRO VALLEY, CALIFORNIA}

Segundo Khemlami (2009), o Sutter Medical Center Castro Valley exemplifica a utilização bem-sucedida de BIM e CM, o empreendimento é uma experiência inovadora em IPD, um marco na Indústria de AECO dos EUA. Destaca-se, ainda, por ser um empreendimento de grande complexidade no valor de 320 milhões de dólares e o primeiro a demonstrar as potencialidades da utilização de ferramentas de Lean Construction, IPD e BIM.

O desenvolvimento do projeto do Sutter Medical Center Castro Valley teve como principais características o uso do IPD, a utilização de métodos de Lean construction, TVD, além de especificar objetivos e metas de projeto para todos os membros da equipe. Tal tipo de abordagem facilita a colaboração ao longo desenvolvimento do projeto e na fase de construção. As exigências e especificações presentes no contrato determinaram o que a equipe de projeto deveria fazer e, consequentemente, controlar as possibilidades de lucro ou perdas. O projeto teve como característica um orçamento reduzido, prazo de entrega curto, metas ambiciosas e a extensiva colaboração durante o detalhamento do projeto e a construção (EASTMAN et al. 2011, p. 431-432).

Alguns dos motivos que alavancaram a utilização de modelos BIM para integrar as equipes de projeto nesse empreendimento foram as diversas metas estabelecidas ao longo do desenvolvimento do empreendimento. Inicialmente, foi assinado um acordo preliminar IFOA (Integrated Form of Agreement) que originou um modelo comprometendo a equipe a utilizar o IPD e ferramentas Lean Construction, que serviu como referência para o desenvolvimento de outros projetos de unidades de saúde (KHEMLAMI, 2009).

Sacks et al. (2010) destacam ainda que houve a presença de um profissional responsável pela integração entre BIM e Lean (BIM Manager). Os resultados positivos demonstram como o novo processo de gerenciamento combinando as duas áreas podem proporcionar benefícios e economia de recursos na execução do empreendimento.

O empreendimento possui alguns itens característicos que se destacam, tais como: as metas de custo a serem cumpridas, a demolição do antigo hospital, a preocupação com a gestão ambiental, o que permitiu diversas certificações LEED e o prazo previsto para o funcionamento do hospital. Para o gerenciamento do empreendimento no desenvolvimento do projeto 
e na construção, houve o uso de ferramentas de Lean Construction - CM e a utilização ampla de modelos BIM (EASTMAN et al. 2011, p. 434).

O uso do IPD foi essencial para atingir as metas estabelecidas pelo proprietário, havendo a participação de todas as equipes envolvidas, permitindo a otimização do projeto e melhorando a colaboração para redução dos custos. O projeto teve como referência um custo-meta, o que facilitou o monitoramento contínuo, garantindo, assim, que essa meta não fosse ultrapassada, tanto antes quanto durante a construção, usando princípios da abordagem do CM (EASTMAN et al. 2011, p. 439).

Maximizar a criação de valor a partir da perspectiva do proprietário, minimizando desperdícios, foi uma prática constante no desenvolvimento desse empreendimento. $\mathrm{O}$ uso de modelos BIM nas fases iniciais de projeto teve como finalidade integrar as equipes de projeto, por meio do modelo BIM, possibilitando a identificação de conflitos e minimizando riscos, desde o detalhamento do projeto à construção, evoluindo até mesmo para a fabricação. A utilização de modelos 3D (Figura 1) para agilizar a troca de informações de projeto tinha também como principal finalidade agilizar a extração de quantitativos e os processos envolvidos na construção, permitindo à equipe um feedback mais rápido do monitoramento do custo-meta (TIWARI et al., 2009).

Tiwari et al. (2009) descrevem como foi o processo de elaboração de um modelo baseado em custos. Percebe-se o uso de ferramentas de modelagem geométrica e geração de desenhos, como Revit Architecture, vinculadas a ferramentas para estimativas de custos como o Timberline Cost Assemblies e Innovaya (Figura 1). A princípio, houve resistência na utilização dos modelos BIM, pois muitos dos especialistas da área de orçamentação não confiavam nas informações geradas de forma automática.

\section{estimativa de custo baseada em modelo de informação}

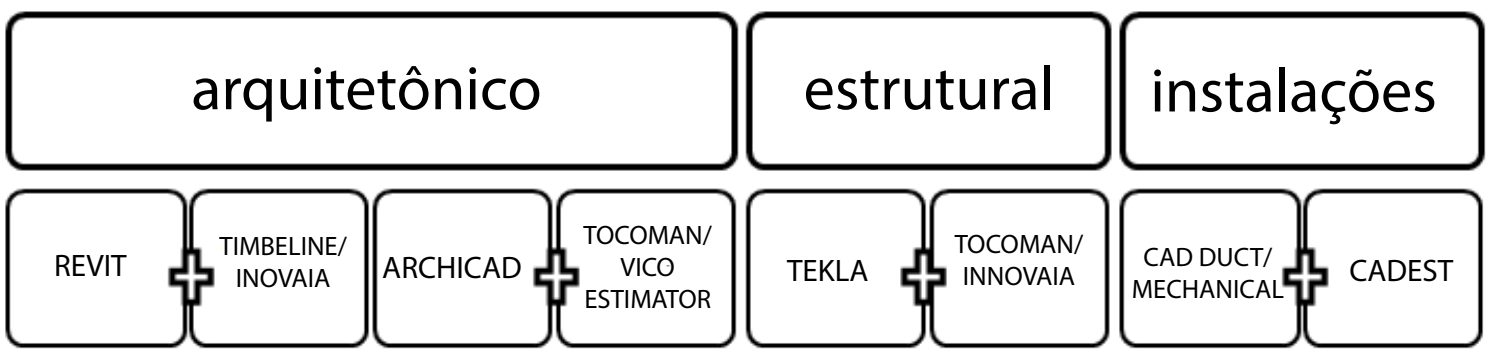

Figura 1. Processo de estimativa de custos realizado no Revit e no Innovaya. Fonte: adaptado de Tiwari e colaboradores (2009, p. 4).
Tiwari et al. (2009, p. 4) afirmam que há no mercado duas opções possíveis na implementação da estimativa de custo baseado em modelo BIM: uma solução de estimativa de custo que trabalha prioritariamente com uma ferramenta de modelagem geométrica (como Timberline e Revit, Tocoman e Tekla, VICO Estimator e ArchiCAD), ou uma plataforma neutra, na qual pode-se importar modelos de diferentes fontes (como Innovaya Visual Estimating, Tocoman, U.S. Cost). Nesse caso, o desenvolvedor do aplicativo de estimativa orçamentária cria um plug-in de exportação para cada software de modelagem geométrica ou usa um formato de arquivo neutro, como o IFC para intercâmbio de dados. Esses aplicativos de estimativa de custos não garantem a exportação para qualquer modelador geométrico, por isso, é necessário verificar a interoperabilidade entre as ferramentas de modelagem e os aplicativos de estimativa de custo.

No início, as estimativas de custos realizadas pelo modelo podem ser mais demoradas, mas, com as devidas verificações dos quantitativos, constatouse maior agilidade, com excelente precisão nas estimativas obtidas de forma automática. Por meio do modelo, foi possível quantificar de forma rápida 
e precisa o custo das alternativas projetuais apresentadas pelas equipes de projeto, facilitando a tomada de decisão, o que contribuiu para a adoção das abordagens do CM desenvolvimento do projeto.

Em um primeiro momento, houve muito retrabalho até que o modelo estivesse apto a gerar informações rápidas e precisas, já que erros na modelagem da edificação acabavam comprometendo a extração dos quantitativos. Como cada parceiro de projeto e construção utilizou uma plataforma BIM específica de sua escolha para modelagem, ao realizar a coordenação, integração e colaboração entre os modelos foi necessário avaliar a conformidade em IFC ${ }^{5}$, para isso foi utilizado o software Solibri Model Checker 6 .

Após a customização dos modelos com o Solibri, para extração dos quantitativos e geração automática dos custos, os integrantes da equipe que trabalharam na orçamentação realizaram um quadro comparando os métodos utilizados: um empregando desenhos e calculando manualmente e o outro executado através da extração automática realizada com modelos BIM. Observa-se na Figura 2 uma redução de até $65 \%$ do tempo ao se utilizar modelos BIM (TIWARI et al., 2009, p. 2).

O desafio era usar os modelos BIM como uma fonte precisa e confiável na extração do custo, o que reduziu o feedback de custo do projeto de 8 para até 3 semanas (Figura 2), porém nem todas as estimativas de custo foram extraídas do modelo. Quando o custo baseia-se em função do tempo e não em elementos 3D, como construção de abrigos provisórios, escoramentos temporários, equipamentos, atividades temporárias, dentre outros, os trabalhadores são dependentes da duração das atividades de construção e dos múltiplos projetos como um todo, tendo reflexos diretos nas atividades (EASTMAN et al., 2011, p. 468).

Além da utilização do BIM para extração de quantitativos, o uso de BIM foi essencial para integrar as equipes principais de trabalho compostas por diversos membros das empresas que participaram do empreendimento: proprietário - Sutter Health; arquiteto - Devenney Group; construtora geral - DPR Construction; engenharia de sistemas mecânicos e hidráulicos - Capital Engineering; projeto elétrico - The Engineering Enterprise; projeto estrutural - TMAD-Taylor \& Gaines; assessoria execução dos projetos mecânicos - Handling Superior Air; assessoria execução dos projetos hidráulicos - J. W. McClenahan; assessoria execução dos projetos elétricos - Morrow Meadows; proteção contra incêndio - Transbay Fire Protection; Projeto de Integração Lean e BIM - GHAFARI Associates (KHEMLANI, 2009).

Ao longo do desenvolvimento do projeto, as equipes e os consultores participaram de reuniões quinzenais, nas quais os modelos eram integrados e avaliados, para isso usou-se o software Navisworks da Autodesk. As reuniões ocorreram de forma colaborativa, as equipes discutiam o projeto em um big room de forma presencial e virtualmente usando tecnologias de colaboração on-line como GoToMeeting ${ }^{\mathrm{TM}}$ ou Webex ${ }^{\mathrm{TM}}$ (EASTMAN et al. 2011, p. 440).

Durante as reuniões, várias análises foram realizadas checando os detalhes construtivos, os fluxos de trabalho, a integração e os conflitos entre as disciplinas. O processo de revisão dos projetos realizados por meio do BIM permitiu a visualização e o acesso de forma fácil a todos os projetos complementares realizados, diferenciando-se, assim, dos processos tradicionais que dependem da interpretação de um conjunto de representações fragmentadas de diversas disciplinas que contêm detalhes específicos (EASTMAN et al. 2011, p. 452).

O Industry Foundation Classes é um modelo de dados com especificação neutra e aberta, não controlada por um único fornecedor ou grupo de fornecedores, definindo um único modelo de dados orientado a objeto de prédios compartilhados para todas as aplicações e compatibilidades. Disponível em: $<$ http://www.buildingsmart.org/>. Acesso em: 28 de julho de 2015.

6 Solibri Model Checker é um software BIM criado para analisar informações de modelos de construção por meio da leitura de seus códigos no formato IFC. É bastante utilizado para a detecção de conflitos e verificação de erros de modelagem (EASTMAN et al. 2011). 
Para facilitar a integração multidisciplinar do projeto, o responsável pela disciplina a ser discutida deveria participar de forma presencial nas reuniões no big room. Sendo assim, as dúvidas referentes à área em questão eram discutidas com os demais membros da equipe, dando maior agilidade ao processo.

As experiências obtidas no Sutter Medical Center Castro Valley demonstram que é possível realizar a integração de equipes de forma colaborativa e contínua com modelos BIM e CM, mesmo em projetos complexos. A utilização conjunta de BIM e CM estabelecida como uma das metas do empreendimento pelo IPD evidencia a sinergia presente nas duas abordagens.

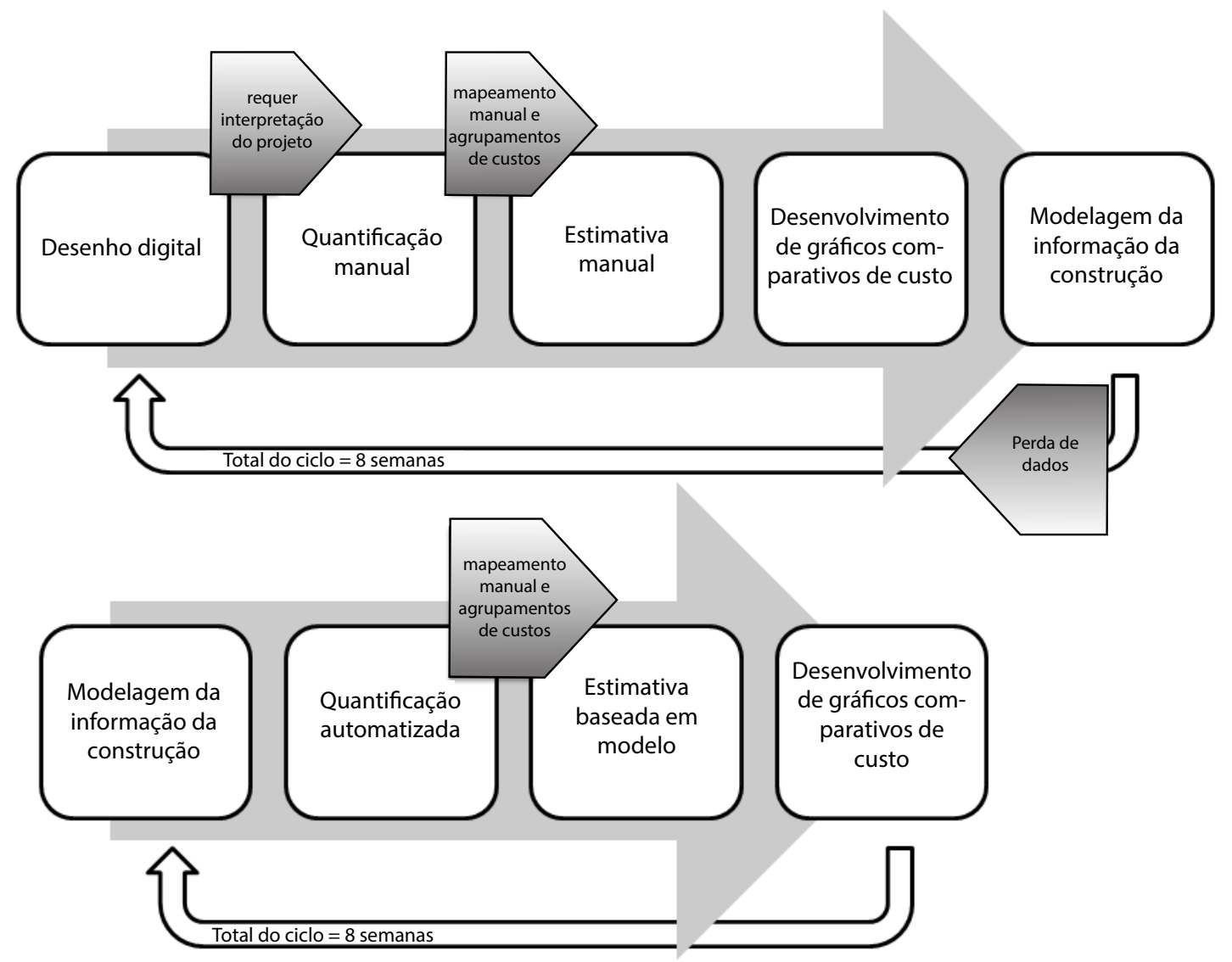

Figura 2. Orçamentação manual comparada com o processo baseado em BIM. Fonte: adaptado de Tiwari e colaboradores (2009, p. 2).
Esse caso explicita a sinergia entre BIM e CM relativa à: (1) extração custos de forma automatizada; (3) colaboração, otimização e controle de processo; (4) rapidez de feedback.

\section{ARGUMENTAÇÃO LÓGICA}

O Quadro 1 apresenta um cenário de utilização conjunta de BIM e CM, a partir dos critérios propostos na metodologia. Na primeira coluna, destacamse as referências bibliográficas dos casos práticos selecionados. Segue ao lado a localização da obra, suas características, a forma de contratação e as práticas específicas utilizadas ao longo do processo. Em seguida, faz-se a classificação das formas de interação utilizadas para atingir o custo-meta.

No Quadro 2, realiza-se a análise da relação entre a utilização de modelagem em BIM e a fase da obra durante a realização da abordagem do CM. Inicia-se com a fase do empreendimento em que o modelo foi realizado (Concepção, Anteprojeto, Projeto, Construção ou Fabricação). Em seguida, 
há a classificação de acordo com o nível de desenvolvimento do modelo de informação e também uma apresentação de algumas características ou nomenclaturas utilizadas para o modelo de custos estabelecido.

Quadro 1. Caracterização dos casos abordados na pesquisa.

\begin{tabular}{|c|c|c|c|c|}
\hline Autores & $\begin{array}{c}\text { Estado, país - } \\
\text { obra }\end{array}$ & $\begin{array}{c}\text { Característica da } \\
\text { obra }\end{array}$ & $\begin{array}{c}\text { Empregos de } \\
\text { contratos e práticas } \\
\text { especificas }\end{array}$ & $\begin{array}{c}\text { Formas de interação para atingir } \\
\text { o custo-meta }\end{array}$ \\
\hline
\end{tabular}

Caso 1: Ballard e Reiser Minesota - EUA (2004). St. Olaf College
Construção de um ginásio para uma universidade
Design Build, práticas de Lean Construction
Workshop para produzir projetos esquemáticos, incorporando metas de custo.
Caso 2: Tiwari et al. (2009);

Khemlani (2009);

Alarcon, Christian e

Tommelein (2011);

Eastman et al. (2011).

Caso 3: Nguyen

(2010).

Caso 4: Nguyen

(2010).

Caso 4': Nguyen

(2010);

Zimina et al. (2012)

Lostuvali, Alves,

Modrich (2012).
California - EUA

Sutter Health

Medical Center

Castro Valley

California - EUA

Seven-story

residential

building

California - EUA

Cathedral Hill

Hospital

California - EUA

Cathedral Hill

Hospital

Construção de um edifício hospitalar

stalação de um sistema de esquadrias de alumínio em um edifício residencial

Parede reforçada contra umidade

Integrated Project Delivery ${ }^{\mathrm{TM}}$ IPD, práticas de Lean construction

Integrated Project Delivery $^{\mathrm{TM}}$ IPD, práticas de Lean Construction e Set-Based Design**

California - EUA Camino Medical Group Montain

Khanzode; Fischer e Reed (2005); Eastman et al. (2008).

Caso 6:

Penamen, Ballard e

Karkkila-Finlândia Santasalo Gears Ltd.
Construção de um edifício hospitalar
Design Build - DB, práticas de Lean Construction e
Set-Based Design.

Não faz referência à forma de contratação Set-Based Design.

Reuniões de trabalho em Grupo big room e virtualmente; integração de toda equipe para atingir as metas de custo propostas. Rastreamento do processo de entrega das esquadrias para eliminar desperdícios.

Simulação e comparação dos processos para redução de custos.

Relatórios A3, tendências de custo. Equipes desenvolvem os principais componentes e sistemas da edificação; integração do projeto em duas reuniões semanais p/evoluções projetuais c/ análises de valor e custo-alvo.

Design Bid Build - DB, Planos de incentivo para a redução dos custos e contingências.

Relatórios A3 para discussão das propostas.

Decisão pelo método escolha por vantagens (CBA - Choosing by advantages).

Fonte: Elaborado pelos autores

*A certificação LEED (Leadership in Energy and Environmental Design) foi criada pelo U. S. Green Building Council (USGBC) para reconhecer as Construções Sustentáveis de acordo com os critérios de eficiência energética design e racionalização de recursos, promovidos pelos empreendimentos certificados. Disponível em: <http://new.usgbc.org/>. Acesso em: 27 jul. 2015. **O Set-Based Design é uma metodologia de projeto em que há a colaboração e comunicação explícita entre os projetistas que pensam de forma conjunta em diversas alternativas de projeto, tanto em nível conceitual como paramétrico. De forma gradual as interações são realizadas diminuindo o número de soluções, eliminando alternativas inferiores até chegar a uma solução final (NGUYEN, 2010). 
Quadro 2. Caracterização da fase de modelagem e nível de desenvolvimento do modelo BIM na abordagem do CM.

\begin{tabular}{|c|c|c|}
\hline Autores & Fase de modelagem & Níveis de desenvolvimento do modelo BIM \\
\hline $\begin{array}{l}\text { Caso 1: Ballard e Reiser } \\
\text { (2004). }\end{array}$ & Concepção e Anteprojeto & $\begin{array}{l}\text { LOD } 100 \text { - modelo volumétrico, } \\
\text { LOD } 200 \text { - modelo esquemático (cost modeling). }\end{array}$ \\
\hline $\begin{array}{l}\text { Caso 2: Tiwari et al. (2009); } \\
\text { Khemlani (2009); } \\
\text { Alarcon, Christian e } \\
\text { Tommelein (2011); } \\
\text { Eastman et al. (2011). }\end{array}$ & $\begin{array}{l}\text { Anteprojeto, Projeto, } \\
\text { Construção e Fabricação }\end{array}$ & $\begin{array}{l}\text { LOD } 200 \text { modelo esquemático, LOD } 300 \text { modelo com geometria } \\
\text { precisa, LOD } 350 \text { Assemblies for Coordination e LOD } 400 \text { modelo } \\
\text { detalhado } \\
\text { (Model-Based Cost Estimating-SMCCV). }\end{array}$ \\
\hline Caso 3: Nguyen (2010). & $\begin{array}{l}\text { Análise do processo } \\
\text { de Projeto, Fabricação, } \\
\text { transporte e montagem }\end{array}$ & $\begin{array}{l}\text { Não foi realizada a modelagem, somente a análise do processo } \\
\text { para possível implementação em Modelo detalhado LOD } 400 \text {. }\end{array}$ \\
\hline Caso 4: Nguyen (2010). & Fabricação & $\begin{array}{l}\text { LOD } 400 \text { modelo detalhado, } \\
\text { Process-Based Cost Modeling (PBCM). }\end{array}$ \\
\hline $\begin{array}{l}\text { Caso 4': Nguyen (2010); } \\
\text { Zimina et al. (2012); } \\
\text { Lostuvali, Alves; Modrich } \\
\text { (2012). }\end{array}$ & $\begin{array}{l}\text { Anteprojeto, Projeto, } \\
\text { Construção e Fabricação }\end{array}$ & $\begin{array}{l}\text { LOD } 100 \text { - modelo volumétrico, LOD } 200 \text { modelo esquemático, } \\
\text { LOD } 300 \text { modelo com geometria precisa, LOD } 350 \text { Assemblies for } \\
\text { Coordination e LOD } 400 \text { modelo detalhado. }\end{array}$ \\
\hline $\begin{array}{l}\text { Caso 5: Rybkowski (2009); } \\
\text { Khanzode, Fischer e Reed } \\
\text { (2005); Eastman et al. } \\
\text { (2008). }\end{array}$ & $\begin{array}{l}\text { Anteprojeto, Projeto, } \\
\text { Construção e Fabricação }\end{array}$ & $\begin{array}{l}\text { LOD } 200 \text { modelo esquemático, LOD } 300 \text { modelo com geometria, } \\
\text { LOD } 350 \text { Assemblies for Coordination e LOD } 400 \text { modelo } \\
\text { detalhado (instalações prediais). }\end{array}$ \\
\hline $\begin{array}{l}\text { Caso 6: } \\
\text { Penamen, Ballard e } \\
\text { Haahtela (2010). }\end{array}$ & Concepção e Anteprojeto & $\begin{array}{l}\text { LOD } 100 \text { - modelo volumétrico e LOD } 200 \text { - modelo esquemático, } \\
\text { ambos com extração automática de custos. }\end{array}$ \\
\hline
\end{tabular}

Fonte: Elaborado pelos autores.

No Quadro 3, realiza-se a caracterização BIM em relação aos benefícios, às evidências de sinergia, às dificuldades e sua classificação em relação à utilização conjunta com a abordagem do CM. Demonstram-se, assim, os benefícios relativos à utilização do BIM no processo associando-os a: (1) custo; (2) criatividade alternativa de solução; (3) colaboração, otimização e controle de processo; (4) rapidez de feedback. Ao final são apresentadas as dificuldades associando-as às barreiras para utilização dos modelos de informação da construção na abordagem do CM, como: (a) pouca capacitação em BIM; (b) baixa interoperabilidade entre softwares; (c) falta de métodos precisos de benchmarking de custos; (d) falta de quantificação dos custos de equipamentos temporários.

Ao analisar o Quadro 1, observa-se um grande número de projetos da área de saúde. Tal fato pode ser explicado pela necessidade de adaptação dos hospitais dos EUA, grande parte deles não está condizente com as adequações necessárias para o grande desenvolvimento tecnológico do setor e das normas CA SB 1953, referente a abalos sísmicos do estado da Califórnia (KHANZODE; FISCHER; REED, 2013).

Como formas de contenção de custos em empreendimentos da área de saúde na Califórnia, novas maneiras de contratação como o IFOA e IPD estão sendo amplamente utilizadas. $\mathrm{O}$ modelo de contrato envolve um acordo entre os proprietários, o arquiteto, a equipe de engenharia e os construtores. Nesse acordo, as equipes de arquitetura, engenharia e construção colocam uma parte significativa de seu lucro em risco. Porém, são incentivados a oferecer soluções criativas e inovadoras para maximizar a qualidade, reduzir os custos e atender às necessidades dos proprietários. As equipes são recompensadas por meio da divisão resultante da contenção de custos que ocorrem ao longo do empreendimento. 
Quadro 3. Caracterização BIM e a abordagem CM em relação aos benefícios e às dificuldades encontradas.

\begin{tabular}{|c|c|c|c|c|}
\hline Autores & Benefícios & $\begin{array}{c}\text { Evidências de } \\
\text { sinergia } \\
\text { BIM e CM }\end{array}$ & Dificuldades & $\begin{array}{c}\text { Caracterização das } \\
\text { barreiras }\end{array}$ \\
\hline
\end{tabular}

$\begin{array}{ll}\text { Caso 1: Ballard e } & \text { - Processo cooperativo; } \\ \text { Reiser (2004). } & \text { - facilidade na extração de } \\ & \text { custos; } \\ & \text { - várias alternativas de } \\ & \text { projeto. }\end{array}$

Caso 2: Tiwari et al. - Rapidez nas informações (2009): Khemlani (2009); Alarcon, Christian e Tommelein (2011); Eastman et al. (2011). referentes ao impacto dos custos nas decisões projetuais;

- suporte ao projeto colaborativo.
(3) das equipes para disseminar o conhecimento e as
(1) competências do projeto.

(2)
(1) - mudança cultural na formação
(4) exigida dos orçamentistas;
(3) - parte dos custos foi levantada manualmente.

Não houve a modelagem.

- Custos de equipamentos temporários não foram extraídos

(3) diretamente do modelo. transporte, montagem detecção de conflitos.

Caso 4': Nguyen
(2010);
Zimina et al. (2012)
Lostuvali, Alves,
Modrich (2012).

- Visualização antecipada das alterações que permite ajustar os custos da obra; - possibilita criar várias soluções;

- BIM é considerado um requisito básico para o desenvolvimento do projeto e da obra.
Caso 5: Rybkowski - Várias alternativas de (2009); Khanzode; Fischer projeto com evidências de custo.
do projeto a partir de dados programáticos;
(2) - capacitação necessária p/ integração e organização entre ferramentas e pessoas.

- Falta um método preciso de benchmarking de custos

- Primeira experiência da equipe

(2) integrando LPDS ${ }^{3}$ e BIM;

(1) - atraso devido a erros na modelagem (desenhos em 2D foram convertidos em 3D -falta de habilidade profissional).

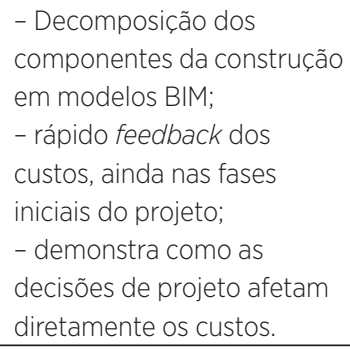

- Falta de pessoas qualificadas que possam gerar modelos de

(3) informação com a complexidade exigida para extração de custos.

)<smiles>CCCC</smiles> 
Na amostra apresentada no Quadro 1 e no Gráfico 1, verificam-se diversas formas de contratação, sendo que a utilização do IPD está presente no caso 2 (Sutter Health Medical Center Castro Valley), no caso 4 (Cathedral Hill Hospital - parede reforçada contra umidade ), e no caso 4' (Cathedral Hill Hospital). Além dessas formas de contratação, verifica-se a utilização de práticas de Lean Construction nos casos citados, como a fixação de metas contratuais para a certificação $L E E D$ do empreendimento, no caso 2 (Sutter Health Medical Center Castro Valley) e a metodologia para o desenvolvimento do projeto Set-Based Design que foi utilizada no caso 4' (Cathedral Hill Hospital).

No caso 1 (St. Olaf College), e no caso 3 (Seven-story residential building), a forma de contratação foi realizada nos moldes do Design Build e foram utilizadas práticas de Lean Construction.

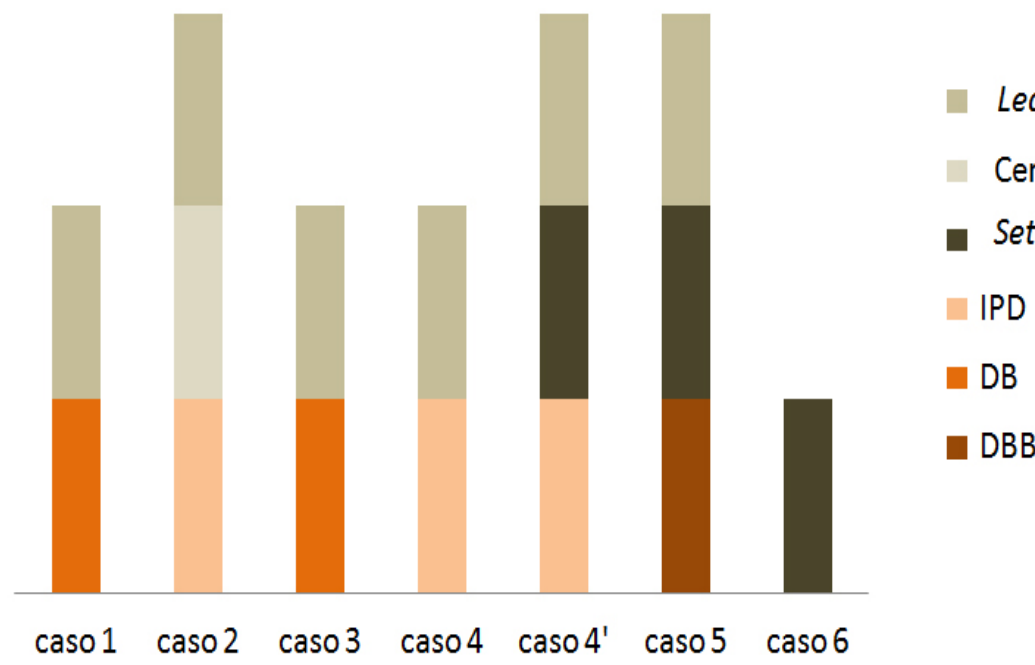

Lean Construction Certificação LEED Set-Based Design IPD DB DBB

Gráfico 1. Tipos de Contratos e práticas específicas. Fonte: elaborado pelos autores.
Somente no caso 5 (Camino Medical Group Montain) utilizou-se como forma de contratação o Design Bid Build. O DBB é um método pouco utilizado em ambientes colaborativos, pois tem como característica o desenvolvimento do processo de forma linear. Inicialmente, o projeto é realizado, posteriormente, ele é orçado e depois executado. Talvez como forma de evitar a segmentação do processo causado pelo DBB foram utilizadas práticas de Lean Construction e o Set-Based Design.

No caso 6 (Santasalo Gears Ltd), não há referência à forma de contratação, porém é mencionada a utilização do método do Set-Based Design para o desenvolvimento do projeto.

Em relação aos níveis de desenvolvimento dos modelos BIM presentes no Quadro 2 e no Gráfico 2, verificou-se que no caso 6 (Santasalo Gears Ltd) e no caso 1 (St. Olaf College) o nível de desenvolvimento do modelo limitou-se ao LOD 100 e LOD 200. Apesar do uso do BIM estar restrito às fases iniciais de concepção. Penamen, Ballard e Haahtela (2010) relatam que é possível definir diretrizes de projeto baseadas no custo-meta proposto ainda nas fases iniciais do projeto, por meio de conexões entre componentes construtivos e tabelas orçamentárias. A possibilidade de criação de diversas alternativas contendo as estimativas de custos facilitou a escolha das melhores soluções de projeto que se aproximaram do custo-meta proposto.

Os níveis de desenvolvimento do modelo no caso 2 (Sutter Health Medical Center Castro Valley) e no caso 5 (Camino Medical Group Montain) concentraram-se em LOD 200, LOD 300, LOD350 e LOD 400. O fato do desenvolvimento do modelo iniciar em LOD 200 está relacionado à fase em que a modelagem do empreendimento se iniciou, que foi após a etapa de concepção, utilizando como referência desenhos digitais para o processo de modelagem BIM. 


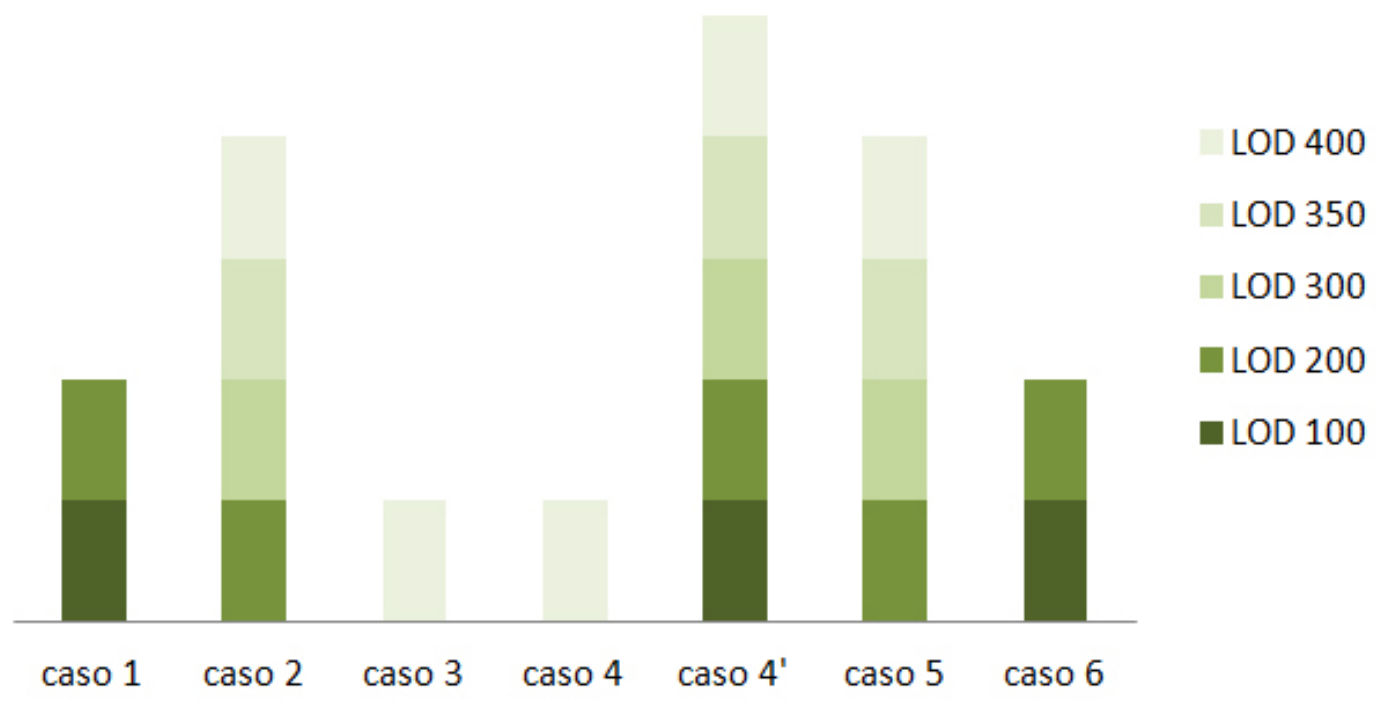

O caso 4' (Cathedral Hill Hospital) iniciou a modelagem nas fases iniciais do projeto utilizando o Revit e alguns modelos CAD 3D, porém somente a equipe responsável pelo desenvolvimento da estrutura metálica usou o modelo para a extração automática de custos nas fases iniciais, as demais equipes geraram desenhos e quantificaram o projeto de forma manual. Verificou-se que o modelo, apesar de não estar totalmente automatizado para extração de custos, auxiliou nas reuniões semanais realizadas para a definição do projeto.

Ao longo do desenvolvimento do projeto do caso 4' (Cathedral Hill Hospital) as informações sobre custo foram sendo adicionadas de acordo com o nível de desenvolvimento do modelo. Esse foi o único caso em que o empreendimento foi modelado do LOD 100 até LOD 400.

Nos níveis mais avançados de desenvolvimento de modelos BIM, algumas situações foram verificadas como: a possibilidade de visualização dos modelos para a detecção de conflitos entre a arquitetura, a estrutura e sistemas prediais, havendo, assim, a integração multidisciplinar das equipes.

No caso 3 (Seven-story residential building) e no caso 4 (Cathedral Hill Hospital - parede reforçada contra umidade) o nível de desenvolvimento do modelo BIM, foi realizado em LOD 400. Dessa forma foi possível realizar a modelagem $4 \mathrm{D}$, que simulou o processo de produção, transporte, montagem e detecção de conflitos dos componentes. Após as simulações de diversas soluções, optou-se pela que permitia a melhor relação entre custo e benefício da atividade que seria realizada (NGUYEN, 2010).

O uso de BIM facilitou a quantificação automática de custos em quase todos os casos, somente no caso 3 (Seven-story residential building) e no caso 4 (Cathedral Hill Hospital - parede reforçada contra umidade) que o processo de quantificação não foi realizado de forma automatizada. Nesses casos, utilizou-se da modelagem $4 \mathrm{D}$ para simular a fabricação, transporte e montagem e, assim, decidir qual a melhor opção a ser adotada ao longo do processo.

Verificou-se então que os níveis de desenvolvimento LOD BIM nos casos estudados foram realizados de acordo com a necessidade de modelagem em relação ao escopo da obra. Ou seja, qual será a função do modelo? O modelo será criado para a concepção do projeto, para extração de custos, checagem de conflitos, simulação 4D, simulação de desempenho, auxiliar no gerenciamento da obra, dentre outros.

Gráfico 2. Níveis de desenvolvimento do modelo BIM. Fonte: elaborado pelos autores. 
Em relação aos benefícios identificados no Quadro 3 e no Gráfico 3 referentes à utilização do BIM e à abordagem do $\mathrm{CM}$, podemos citar que no caso 1 (St. Olaf College), no caso 2 (Sutter Health Medical Center Castro Valley), no caso 3 (Seven-story residential building), no caso 4 (Cathedral Hill Hospital - parede reforçada contra umidade), no caso 4' (Cathedral Hill Hospital) e no caso 6 (Santasalo Gears Ltd), o modelo BIM facilitou o processo de integração e colaboração entre as equipes do empreendimento, otimizando o controle do processo.

Outro benefício relatado referente ao uso do BIM foi o desenvolvimento de várias alternativas e soluções para um mesmo projeto, ampliando, assim, os cenários mais favoráveis que possibilitam a contenção de despesas em busca de uma solução otimizada em custo e valor. Esses benefícios foram alcançados por meio de workshops contendo projetos, esquemáticos e metas de custo no caso 1 (St. Olaf College), e por meio do Set-Based Design, método utilizado nos casos 4' (Cathedral Hill Hospital), 5 (Camino Medical Group Montain) e 6 (Santasalo Gears Ltd).

rapidez de feedback

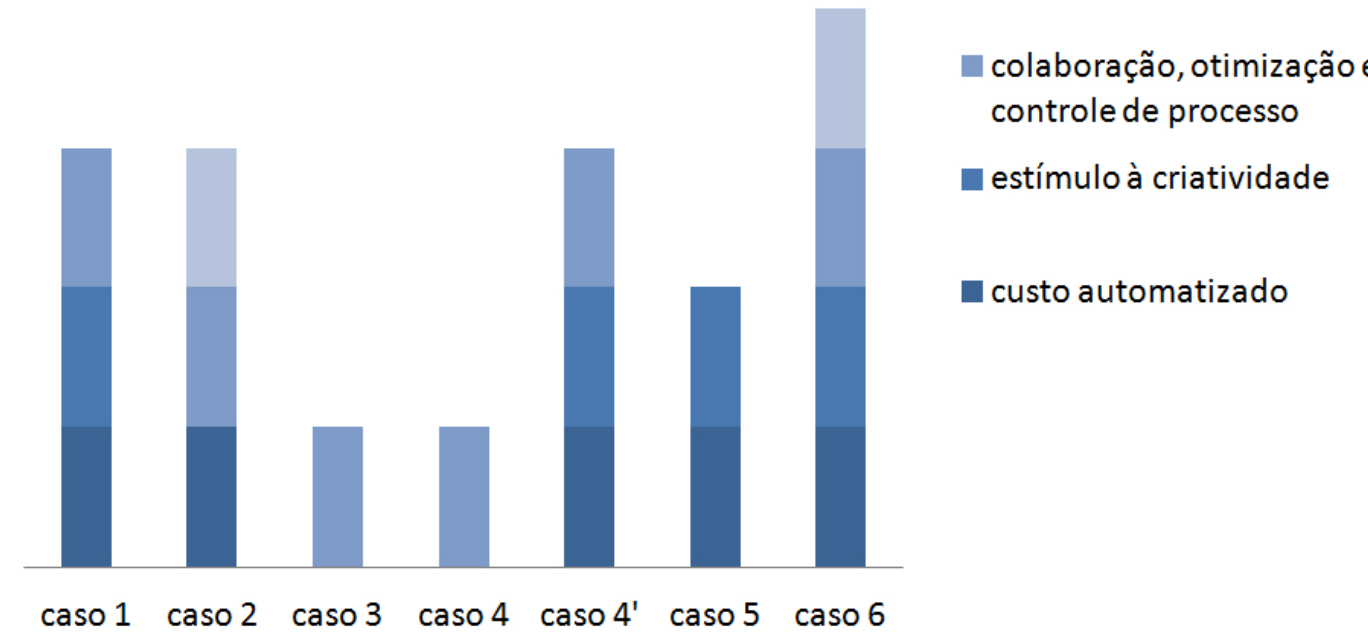

Gráfico 3. Benefícios de BIM no CM. Fonte: elaborado pelos autores.
Em específico no caso 6 (Santasalo Gears Ltd), a decomposição de componentes da construção em modelos BIM auxiliou no processo de extração de custos e apoiou as práticas de Set-Based Design com a rapidez no feedback de custos.

Destaca-se ainda na utilização conjunta de BIM e CM: a coordenação dos projetos de instalação predial que requerem geometria precisa, evitando conflitos, a necessidade de informação precisa para projetos as built e futuros retrofits e a integração da equipe ao modelo de custos (fundamental para simulação de alternativas de projeto, análises de custo e valor entregue). Tais práticas demonstram como BIM é essencial para as práticas colaborativas com CM.

Em relação às dificuldades e barreiras para implementação de BIM e CM identificadas no Quadro 3 e no Gráfico 4, verifica-se que apenas no caso 3 (Seven-story residential building) e no caso 4 (Cathedral Hill Hospital parede reforçada contra umidade) não são relatados problemas relativos à baixa capacitação de profissionais na área de BIM. Tal fato pode ser explicado pelo foco específico na modelagem 4D nesses casos.

Além da falta de capacitação de pessoal em BIM relatada no caso 2 (Sutter Health Medical Center Castro Valley) e no caso 4'(Cathedral Hill Hospital), a baixa interoperabilidade entre softwares é outro fator que acaba sendo 
influenciado pela capacitação de profissionais na área de TI, que poderiam otimizar os problemas e conflitos gerados.

No caso 4' (Cathedral Hill Hospital) é relatada a falta de métodos precisos de benchmarking de custos. Nguyen (2010) cita a necessidade de se criar métodos que utilizem como referência as melhores práticas para extração de custos por meio de modelos BIM e CM e propõe em seu trabalho um modelo teórico que auxilie essa integração.

São mencionadas no caso 2 (Sutter Health Medical Center Castro Valley) e no caso 4 (Cathedral Hill Hospital - parede reforçada contra umidade) as dificuldades de quantificação de elementos temporários com modelos BIM. A estimativa baseada no modelo da construção não consegue relacionar as atividades relativas ao tempo (construção de abrigos provisórios, escoramentos temporários, equipamentos, atividades temporárias, dentre outros), para isso, seria necessário elaborar um modelo 4D contendo esses elementos e as atividades relacionadas a eles.

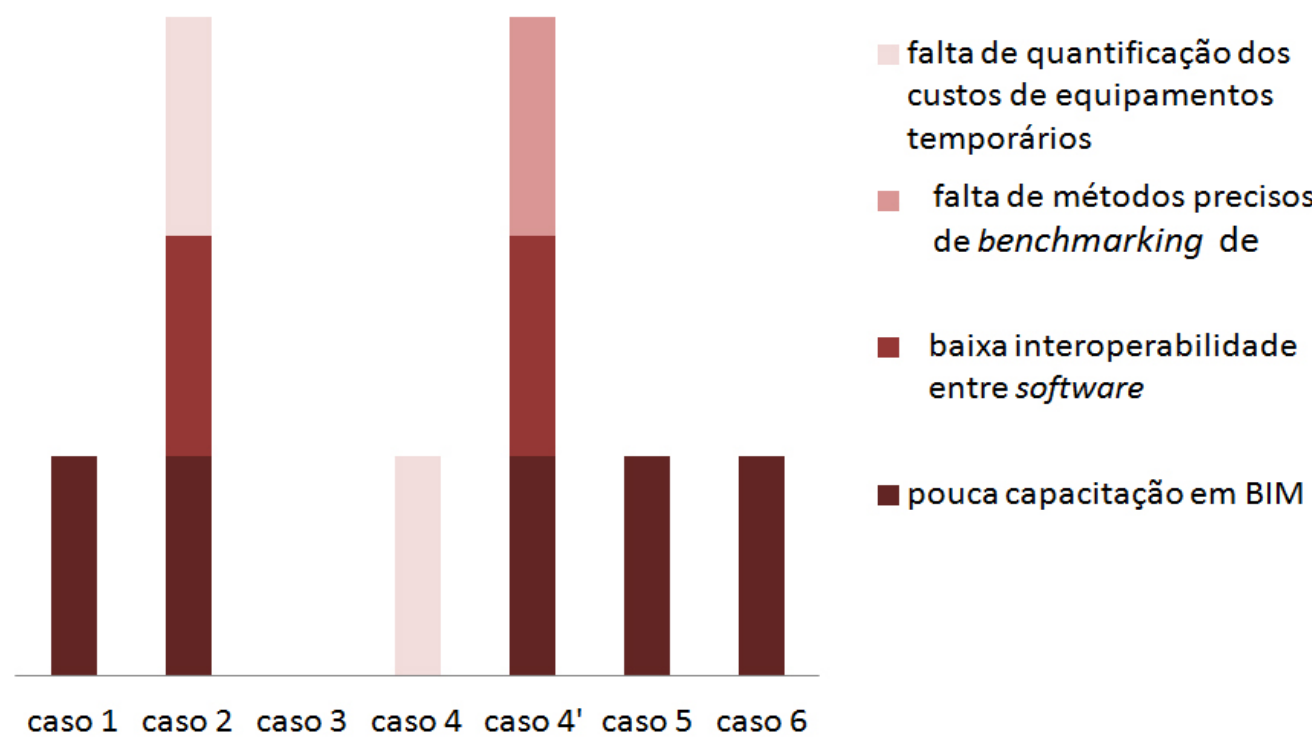

As dificuldades relatadas e classificadas no Quadro 3, referentes ao uso

Gráfico 4. Barreiras para implementação de BIM no CM. Fonte: elaborado pelos autores de BIM, concentram-se principalmente na falta de pessoal qualificado e experiente em BIM. Como BIM pode ser relacionado a uma mudança de paradigma, a indústria de AECO deverá, aos poucos, suprir essa demanda que contempla novas formas de contratação e gerenciamento, as quais são impulsionadas por experiências práticas que demonstram bons resultados, como o caso 2 (Sutter Health Medical Center Castro Valley).

Analisando o Gráfico 5, que relaciona os benefícios de BIM no CM, os tipos de contratos e as práticas específicas, percebe-se que não há uma relação direta entre os tipos de contratos e os benefícios com BIM. De todos os casos acima analisados, somente no caso 1 (St. Olaf College), no caso 2 (Sutter Health Medical Center Castro Valley), e no caso 4' (Cathedral Hill Hospital) aparecem três tipos de benefícios de BIM no CM. Os três casos possuem formas distintas de contratação, o primeiro DB, o segundo e o terceiro IPD não menciona se há uma forma de contratação específica. Somente no caso 6 (Santasalo Gears Ltd) aparecem 4 tipos de benefícios e não é mencionada a forma de contratação.

Percebe-se nos casos citados que, além da forma de contratação, é importante verificar se há práticas integradas e metas integradas ao contrato, o que pode alavancar o processo colaborativo e proativo essencial para o $\mathrm{CM}$. 


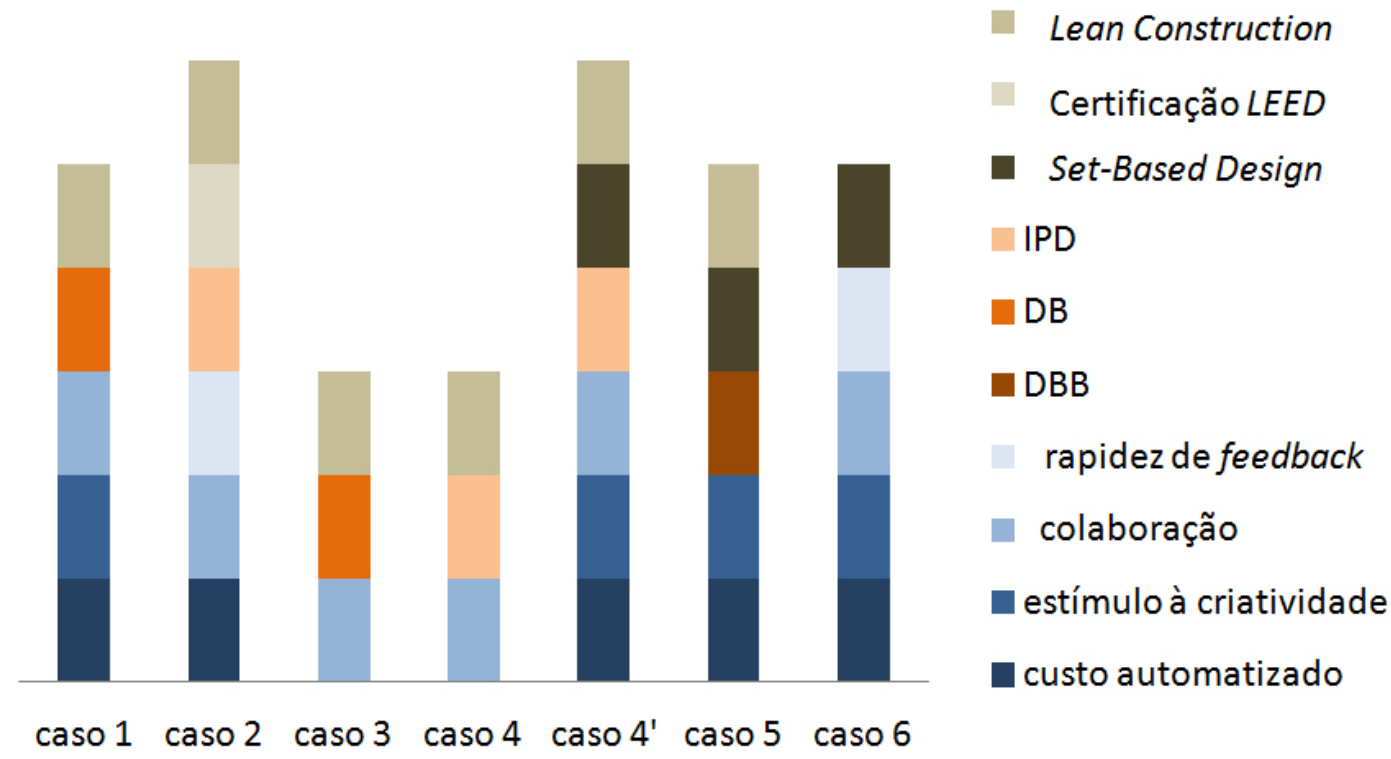

Gráfico 5. Benefícios de BIM no $\mathrm{CM}$, tipos de contratos e práticas específicas. Fonte: elaborado pelos autores.
Como CM é uma abordagem proativa, necessita de ampla colaboração, o uso de BIM age como um catalisador desse processo, permitindo o envolvimento de todos os agentes nas fases inicias do projeto e ao longo do processo. Sendo assim, parte dos resultados positivos alcançados nos empreendimentos, relacionados no estudo, pode estar diretamente relacionada não somente às formas de contratação, mas também às práticas específicas e metas estabelecidas que prezam pela colaboração e propiciam a interação dos agentes como: o Integrated Project Delivery (IPD), o Design Build (DB) ${ }^{7}$, e as práticas de Lean Construction e do Set-Based Design.

Sacks et al. (2010), ao utilizarem uma matriz que justapõe funcionalidades BIM com princípios de Lean Construction, identificaram um total de 56 interações. Os autores acima citados afirmam ainda que há diversos exemplos de utilização de BIM sem IPD ocorrendo de formas dissociadas em alguns casos. Porém, BIM é essencial para atingir um nível eficiente de colaboração necessária para realizar o IPD.

O Gráfico 6 demonstra a relação entre os benefícios de BIM no $\mathrm{CM}$ e os níveis de desenvolvimento do modelo da informação da construção, nesse caso é proeminente a relação entre os níveis de desenvolvimento do modelo e os benefícios descritos ao longo do processo. Os casos que possuem três ou mais benefícios relatados (caso 1, caso 2 e caso 4'), começaram a desenvolver o modelo nas fases iniciais de projeto em LOD 100. Dois desses casos relatados descrevem apenas a modelagem realizada na fase de concepção do projeto em LOD 100 e LOD 200: no caso 1, (St. Olaf College) são relatados 3 benefícios e no caso 6 (Santasalo Gears Ltd) são relatados 4 benefícios.

Constatou-se, assim, que a utilização de BIM e CM podem ocorrer em todas as fases de um empreendimento, e que o nível LOD está vinculado às metas estabelecidas no início do projeto, dessa forma, a evolução do detalhamento do modelo reflete diretamente na evolução das propostas, rediscussão e contenção de custos. Porém a utilização de BIM nas fases iniciais do projeto permite o desenvolvimento rápido e preciso de várias soluções de projeto, estimulando a criatividade e o trabalho em equipe. BIM pode ainda gerar estimativas de custos mais precisas, dando suporte ao processo de tomada de decisão nas fases iniciais do projeto, essencial na abordagem do CM.

Segundo Becerik-Gerber e Rice (2010, p. 190), apesar do DB ser um método promissor na colaboração entre as equipes por envolver o projeto e a construção, o IPD é apontado como o cenário mais favorável para a colaboração e o uso do BIM, pois permite alinhar os objetivos das equipes de trabalho com contratos de incentivo. 


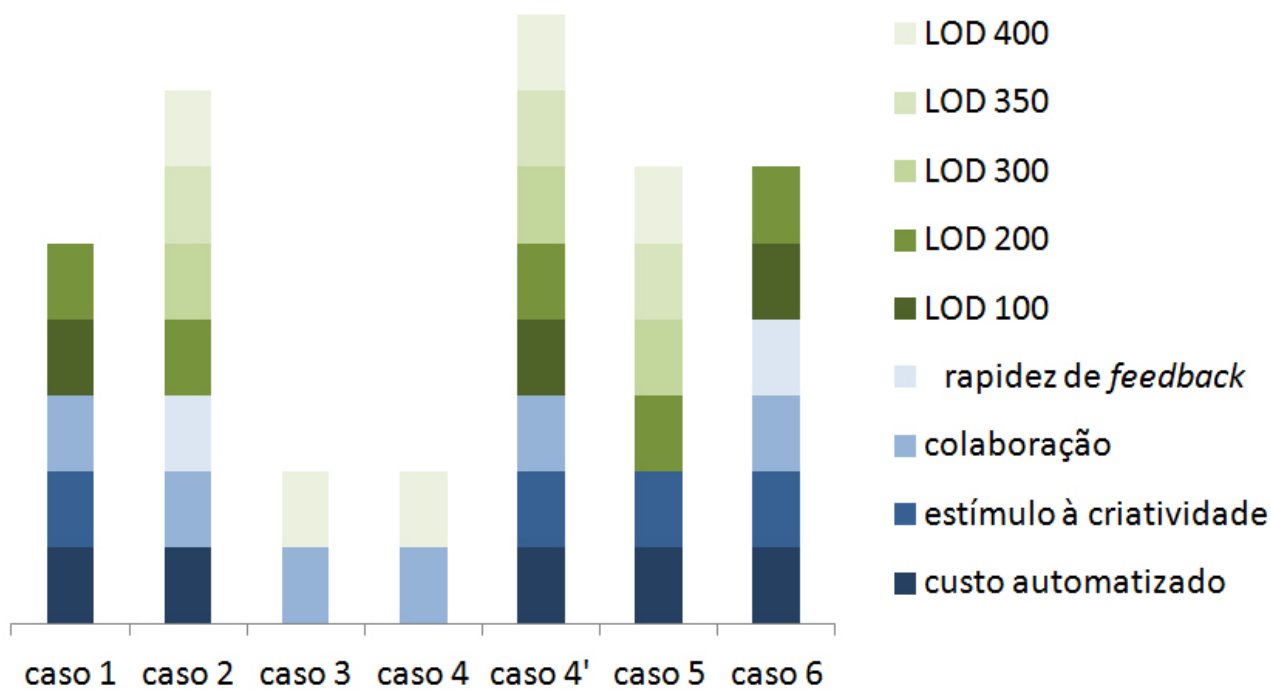

\section{CONCLUSÕES}

Após uma revisão bibliográfica, o presente artigo selecionou sete casos de adoção conjunta de BIM e CM. Após a seleção, foi apresentado um quadro e dois gráficos comparativos, o que permitiu levantar as evidências que demonstram a sinergia entre as abordagens BIM e CM por meio da argumentação lógica proposta por Groat e Wang (2002), destacando-se os principais benefícios, suas relações com as formas de contratação e níveis de desenvolvimento do modelo da informação da construção e as barreiras para implementação das abordagens de forma conjunta.

Comprova-se nos exemplos acima uma grande sinergia entre o uso de modelos da informação da construção e a abordagem do CM, sendo que em $70 \%$ dos casos analisados constata-se o uso de novos tipos de contratação como IPD e em $100 \%$ dos casos o uso de práticas ou metas específicas, como Lean Construction e Set-Based Design, as quais estimulam princípios de colaboração e amplo comprometimento das equipes de projeto, fornecedores e obra, essenciais na abordagem do CM e alavancados com BIM.

Em relação às informações referentes aos custos de um empreendimento essenciais para a abordagem do CM, o uso de BIM em 70\% dos casos relatados deu suporte ao processo de orçamentação pela automatização de modelos para extração rápida e precisa dos quantitativos. Dessa forma, apoiou a análise do custo-meta, subsidiando, assim, o processo de tomada de decisão nas fases iniciais e no desenvolvimento do empreendimento. Os demais casos utilizaram BIM para visualização do processo em $4 \mathrm{D}$, o que possibilitou avaliar qual solução teria o melhor custo benefício.

Outro fato que chama a atenção é o desenvolvimento de práticas colaborativas integradas por meio de modelos BIM presentes em $85 \%$ dos casos, o que permite a otimização, colaboração e controle do processo de desenvolvimento do empreendimento, auxiliando no processo de gerenciamento e análise para contingência de recursos, essencial ao CM.

A possibilidade de criação de diversas soluções com BIM, de forma colaborativa, com comunicação explícita entre os projetistas, que pensam de forma conjunta, tanto em nível conceptual como paramétrico, são ações que provêm do Set-Based Design, presente em $40 \%$ dos casos. Essas ações estimulam a criatividade e a produção de soluções otimizadas em custo e valor ainda nas fases iniciais do projeto, destacando-se, dentre os casos que apresentaram a melhor performance de benefícios, os que adotaram o uso de BIM logo nas fases iniciais do projeto.

Verifica-se que uma das maiores dificuldades de integração entre 0 BIM e o CM está relacionada à capacitação de pessoal e às dificuldades no
Gráfico 6. Benefícios entre BIM e CM, e níveis de desenvolvimento do modelo BIM. Fonte: elaborado pelos autores. 
processo de criação do modelo de custos, que irá subsidiar o processo. Tais dificuldades estão relacionadas à interoperabilidade entre as ferramentas e à falta de históricos de custos que devem ser desenvolvidos nas empresas, essenciais na implementação de CM e BIM.

Outro fator determinante em relação à falta de mão de obra qualificada na área de BIM é justificada pela mudança de paradigma no setor, a crescente demanda do mercado, a adequação dos cursos de arquitetura e de engenharia civil para implementação do BIM e, finalmente, a especialização de profissionais capacitados para gerenciar os processos BIM com o BIM manager.

Percebe-se que, na maioria dos casos estudados, o uso de BIM fica subentendido como um requisito básico para alavancar e apoiar as práticas da abordagem do CM. Em outras palavras, CM demanda o uso de BIM, que por sua vez media o CM. Constatou-se que a utilização de modelos BIM é essencial para agilizar a extração de quantitativos e os custos apoiando o processo de tomada de decisão, inerente ao $\mathrm{CM}$.

A pesquisa também sinaliza a importância da combinação de conceitos já apresentados em estudos isolados. $\mathrm{O}$ estudo secundário realizado com base em revisão de literatura forneceu uma perspectiva ampla em relação às evidências que podem comprovar a sinergia e as conexões possíveis entre os conceitos de CM e BIM, difíceis de serem cogitadas a partir da análise isolada de cada estudo.

\section{AGRADECIMENTOS}

À CAPES, pela concessão de uma bolsa de estudos de doutorado.

\section{REFERÊNCIAS}

ALARCON, I.; CHRISTIAN, D.; TOMMELEIN, I. D. Collaborating with a permitting agency to deliver a healthcare project: case study of the Sutter Medical Center Castro Valley (SMCCV). In: ANNUAL CONFERENCE OF THE INTERNATIONAL GROUP FOR LEAN CONSTRUCTION, 19, 2011, Lima. Proceedings... Lima: Pontifícia Universidad Católica del Perú, 2011, v. 1. p. 402-415, jul. 2011. Disponível em: <http://www.iglc.net/ Papers/Conference/21>. Acesso em: 20 mar. 2013.

AMERICAN INSTITUTE OF ACHITECTS (Org.). Document E202 ${ }^{\mathrm{TM}}$ : Building Information Modeling Protocol Exhibit, California, AIA, 2008, p. 9. Disponível em: <http://www.aia. org/groups/aia/documents/pdf/aiab083007. pdf>. Acesso em: 14 mar. 2013.

AMERICAN INSTITUTE OF ACHITECTS. Guide, Instructions and Commentary to the 2013 AIA Digital Practice_Documents. California: AIA, 2013, p. 62. Disponível em: <http://www.aia.org/groups/aia/documents/ pdf/aiab095711>. Acesso em: 06 de jan. 2015.

ANSARI, S.; BELL, J. E.; CAM-I Target Costing Group. Target costing: the next frontier in strategic cost management. Chicago: Irwin, 1997. $250 \mathrm{p}$

BALLARD, G. The Lean Project Delivery System: an update. Lean Construction
Journal, Arlington, p. 1-19, 2008. Disponível em: $\quad<$ http://www.leanconstruction.org/ media/docs/lcj/2008/LCJ_08_001.pdf>. Acesso em: 25 mar. 2013.

BALLARD, G.; REISER, P. The St. Olaf College field house project: a case study in designing to target cost. In: ANNUAL CONFERENCE OF THE INTERNATIONAL GROUP FOR LEAN CONSTRUCTION, 12., 2004, Helsingore. Proceedings... Helsingore: IGLC, ago. 2004. p. 234-249. Disponivel em: <http://www.iglc.net/ Papers/Details/325>. Acesso em: 20 mar. 2013.

BECERIK-GERBER, B.; RICE, S. The Perceived Value of Buliding Information Modeling in the U.S. Building Industry. Journal of Information Technology in Construction. v. 15, p. 185-201, 2010.

BEDRICK, J. A level of development specification for BIM Processes. $n$, Santa Clara, v. 68, p. 1-9, maio 2013. Disponível em: <http://www.aecbytes.com/viewpoint/2013/ issue_68.html>. Acesso em: 15 mar. 2013.

BEDRICK, J. Organizing the development of a building information model. AECbytes: Futures, Santa Clara, v. 20, p. 1-4, agosto 2008. Disponivel em: <http://www.aecbytes. com/feature/2008/MPSforBIM.html>. Acesso em: 15 mar. 2013. 
COOPER, R.; SLAGMULDER, R. Target costing and value engineering. Portland: Productivity Press, 1997. 379 p.

EASTMAN, C. et al. BIM Handbook: A guide to Building Information Modeling for owners, managers, designers, engineers, and contractors. Hoboken: John Wiley \& Sons, 2008. 490p.

BIM Handbook: A guide to Building Information Modeling for owners, managers, designers, engineers, and contractors. 2. ed. Hoboken: John Wiley \& Sons, 2011. 650 p.

GIL, A. C. Como elaborar projetos de pesquisa. 5. ed. São Paulo: Atlas, 2010. 184 p.

GROAT, L.; WANG, D. Architectural research methods.New York: ohn Wiley \& Sons, 2002. 480p

JACOMIT, A. M.; GRANJA, A. D. An investigation into the adoption of target costing on Brazilian public social housing projects. Architectural Engineering and Design Management, v. 7, n. 2, p. 113-127, 2011.

KHANZODE, A.; FISCHER, M.; REED, D. Case study of the implementation of the Lean Project Delivery System (LPDS) using virtual building technologies on a large healthcare project. In: ANNUAL CONFERENCE OF THE INTERNATIONAL GROUP FOR LEAN CONSTRUCTION, 13, 2005, Sydney. Proceedings... Sydney: IGLC, v. 1. p. 153-160, jul. 2005. Disponível em: <http://www.iglc. net/Papers/Conference/15>. Acesso em: 20 mar. 2013.

KHEMLANI, L. Sutter Medical Center Castro Valley: Case Study of an IPD Project. AECbytes: Building the Future, v. 6, mar. 2009. Disponivel em: <http://www.aecbytes. $\mathrm{com} /$ building thefuture/2009/Sutter IPDCaseStudy.html >. Acesso em: 15 mar. 2013.

LEITE, F.; AKCAMETE, A.; AKINCI, B.; ATASOY, G.; LIKISITAS, S. Analysis of modeling effort and impact of different levels of detail in building information models. Automation in Construction, v. 20, p. 601-609, 2011.

LOSTUVALI, B.; ALVES, T. C. L.; MODRICH, R. Lean Product Development at Cathedral Hill Hospital Project. In: Annual conference of the International Group for Lean Construction, 20, 2012, San Diego. Proceedings... San Diego, v. 1, p. 1041-1050, jul. 2012.

MACOMBER, H.; HOWELL, G.; BARBERIO, J. Target Value Design: Nine Foundational Practices for Delivering Surprising Client Value. California: The American Institute of Architects, 2007. 4 p. (Practice Management Digest).
MONDEN, Y. Target costing and Kaizen Costing. Portland: Productivity Press, 1995. $373 p$

NICOLINI, D.; TOMKINS, C.; HOLTI, R.; OLDMAN, A.; SMALLEY, M. Can target costing and whole life costing be applied in the construction industry?: evidence from two case studies. British Journal of Management Londres, v. 11, n. 4, p. 303-324, dez. 2000.

NGUYEN, H. V. Process-based cost modeling to support Target Value Design 2010. 175 f. Tese (Doutorado em Engenharia Civil e Ambiental) - University of California, Berkeley, 2010

OKANO, H., SUZUKI, T. A history of Japanese management accounting. In: CHAPMAN, C.

S.; HOPWOOD, A. G.; SHIELDS, M. D. Handbook of Management Accounting Research. Oxford: Elsevier, 2007. p. 1119-1137.

PENAMEN, A.; BALIARD, G.; HAAHTELA, Y. Designing to Targets in a Target costing process. In: ANNUAL CONFERENCE OF THE INTERNATIONAL GROUP FOR LEAN CONSTRUCTION, 18., 2010, Haifa. Proceedings... Haifa: Technion, jul. 2010. v. 1, p. 161-170.

RYBKOWSKI, Z. K. The application of root cause analysis and Target Value Design to evidence-based design in the capital planning of healthcare facilities. 2009. 264 f. Tese (Doutorado em Engenharia Civil e Ambiental) - University of California, Berkeley, 2009.

SACKS, R. et al. Interaction of Lean and Building Information Modeling in Construction. Journal of Construction Engineering and Management, v. 136, n. 9, p. 968-980, 2010

TIWARI, S.; ODELSON, J.; WATT, A. KHANZODE A. Model-based estimating to inform Target Value Design. AECbytes: Building the Future, v. 12, ago. 2009. Disponivel em: <http://www.aecbytes.com/buildingthefuture/2009/ModelBasedEstimatingtolnformTargetValueDesign>. Acesso em: 5 jun. 2012.

WINCH, G. Managing Construction Projects: an information processing approach. Oxford: Blackwell Science, 2002. p. 457.

YOOK, K.; KIM, I.; YOSHIKAWA, T. Target costing in the construction industry: evidence from Japan. Construction Accounting \& Taxation, v. 15, n. 3, maio/jun. 2005, p. 5

ZIMINA, D.; BALLARD, G.; PASQUIRE, C. Target value design: using collaboration and a Lean approach to reduce construction cost. Construction Management and Economics, v. 30, n. 5, p. 383-398, maio 2012.
Marcelo de Morais arammorais@uol.com.br

Ariovaldo Denis Granja adgranja@fec.unicamp.br

Regina Coeli Ruschel ruschel@fec.unicamp.br 